\title{
The Real-World Safety and Efficacy of Directly Acting Antiviral Therapy for the Treatment of Patients with Hepatitis C Infection and Decompensated Cirrhosis
}

\author{
NOURA M. GHAREEB, M.Sc.; MAMDOUH A. GABR, M.D. and AMAL A. SELIM, M.D.
}

The Department of Internal Medicine, Faculty of Medicine, Tanta University

\begin{abstract}
Background: HCV was considered a major health problem worldwide before the discovery of direct acting antiviral therapy. Patients with chronic HCV and decompensated cirrhosis are not uncommon and represent the greatest therapeutic challenge.
\end{abstract}

Aim of Study: The primary aim of this study is to assess safety, efficacy and tolerability of all oral DAAs in the treatment of a group of difficult-to-treat population (HCV genotype 4-related decompensated cirrhosis).

Patients and Methods: Forty (40) patients with chronic $\mathrm{HCV}$ infection and decompensated cirrhosis received different combinations of direct acting antivirals in the form of of sofosbuvir-daclatasvir and sofosbuvir-ledipasvir \pm ribavirin for 24wks (for the regimens not containing ribavirin) and $12 \mathrm{wks}$ (for the regimens containing ribavirin).

All patients in this study were subjected to: History taking regarding demographic data and risk factors predisposing them to HCV infection, full clinical examination, laboratory investigations (CBC, liver functions, PT and INR), CTP scoring before treatment and $12 \mathrm{wks}$ after the end of treatment (SVR).

Results: Thirty (30) patients complete the duration of treatment and developed Sustained Virological Response (SVR) and those patients showed a significant improvement clinically regarding amount of ascites $(p=<0.01)$, in laboratory findings regarding platelets count $(p=<0.05)$, liver transaminases $(p=<0.05$ for ALT and AST), serum albumin level $(p=<0.05)$ and CTP $(p=<0.01)$.

Conclusion: Direct acting antivirals are highly effective and showed great improvement in patients with chronic hepatitis $\mathrm{C}$ and decompensated cirrhosis clinically and in laboratory findings.

Key Words: Direct acting antivirals - Hepatitis C.

Correspondence to: Dr. Noura M. Ghareeb,

The Department of Internal Medicine, Faculty of Medicine, Tanta University

\section{Introduction}

THE discovery of DAAs represented a revolution in the management of chronic HCV infection [1]

Among patients with chronic hepatitis $\mathrm{C}$, those with decompensated cirrhosis represent the greatest therapeutic challenge [2]. Additionally, HCV G4 patients with decompensated cirrhosis not attracted as much attention in large scale clinical trials as that afforded to other HCV genotypes [3] .

Moreover, the the safety, tolerability and efficacy of DAAs regimens have not been extensively studied in patients with decompensated cirrhosis [4].

Thus, patients with decompensated disease were largely untreated and the decision to treat them may be difficult. Such patients present a complex clinical issue that dictates that experienced personnel administer therapy if at all possible [5]

Therefore, this real-world, open label, observational study was conducted to assess the efficacy and safety of DAAs therapy in the treatment of a group of Egyptian patients with chronic hepatitis C genotype 4 and decompensated cirrhosis.

\section{Subjects and Methods}

In the period from March 2017 to September 2017, a total of 40 Egyptian patients with chronic HCV genotype 4 infection and decompensated cirrhosis which were the subject of the present study were selected and identified from Tanta Liver Center and outpatient clinic of Internal Medicine Department Tanta University. 
All the study group were subjected to the following:

1- Full history taking including risk factors of $\mathrm{HCV}$ infection.

2- Complete physical examination searching for stigmata of liver cirrhosis and signs of decompensation.

3- Laboratory studies including: Urine, CBC, ranom blood sugar, prothrombin time, prothrombin activity, serum bilirubin, ALT, AST, serum albumin and viral markers including $\mathrm{HCV} \mathrm{Ab}$, HBs Ag and HCV RNA by RT PCR.

\section{4- Ultrasound scan.}

5- The severity of liver cirrhosis was determined by estimation of Child-Turcotte-Pugh (CTP) score depending on clinical, biochemical and US findings.

6- Treatment regimen: All the study group were treated with an all oral fixed dose of either Sofosbuvir (400mg) + Ledipasvir (90mg) or Sofosuvir (400mg) + Daclatasvir (60mg) (according to which of them available) \pm ribavirin for either 12 or $24 \mathrm{w}$ according to ribavirin use.

The ribavirin dose was 1000 or $1200 \mathrm{mg}$ in patients $<75$ or $\geq 75 \mathrm{~kg}$ respectively or $600 \mathrm{mg}$ for all patients with a hemoglobin level $<12 \mathrm{gm} / \mathrm{dl}$. The primary end point is Sustained Virologic Response (SVR) at 12 weeks after the end of treatment (SVR 12). 32 patients $(80 \%)$ were treated with Sofosbuvir (400mg) plus Ledipasvir (90mg) \pm Ribavirin and the remaining $8(20 \%)$ patients were treated with Sofosuvir (400mg) plus Daclatasvir $(60 \mathrm{mg}) \pm$ Ribavirin for either 12 or $24 \mathrm{w}$ according to ribavirin use.

Also, treatment-related adverse events as well as any complications observed during the study were recorded.

\section{Results}

-Values are expressed as mean $\pm S D ; n=30$.

- The significance of difference was analyzed by one-way ANOVA and Tukey test using computer Graph Pad InStat.

- ANOVA was significant at $p<0.05$.

- Group having (***) were significant at $p<0.001$.

- Group having (**) were significant at $p<0.01$.

- Group having (*) were significant at $p<0.05$.

- Otherwise insignificants at $p>0.05$.
Flow diagram of patients throughout the 6 month study period.

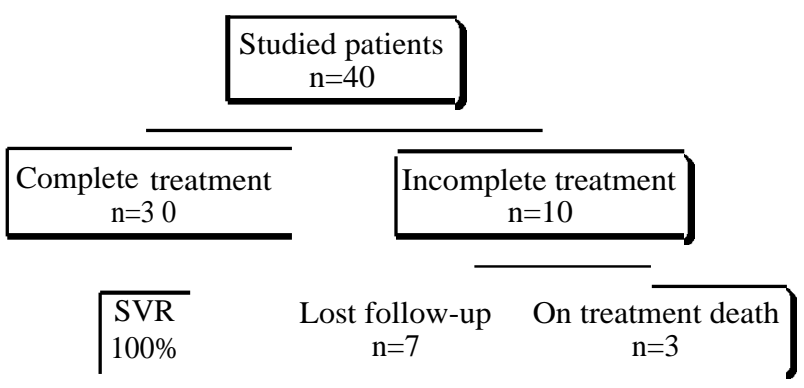

Table (1): Demographic data of the studied group $(n=40)$.

\begin{tabular}{lll}
\hline Item & No. & $\%$ \\
\hline Age: & & \\
Range & $29-76 y$ & \\
Mean \pm SD & $57.78 \pm 10.95$ & \\
Sex: & & \\
Male & 24 & 60 \\
Female & 16 & 40 \\
Residence: & & \\
Rural & 40 & 100 \\
Urban & 0 & 0 \\
Risk factors of HCV infection: & & \\
Dental procedures & 14 & 35 \\
Surgery & 12 & 30 \\
Blood transfusion & 6 & 15 \\
Endoscopy & 6 & 15 \\
Family history & 5 & 12.5 \\
IV antibilharzial ttt & 3 & 7.5 \\
Comorbidity: & & \\
DM & 13 & 32.5 \\
Heart disease & 2 & 5 \\
Previous treatment: & & \\
Treatment naïve & 40 & 100 \\
Treatment experienced & 0 & 0 \\
\hline
\end{tabular}

Table (2): Clinical characteristics of studied group ( $n=40)$.

\begin{tabular}{lcl}
\hline Item & Number $(\mathrm{n}=40)$ & $\%$ \\
\hline Lower limb edema & 39 & 97.5 \\
Palmar erythema & 31 & 77.5 \\
Hepatic encephalopathy & 13 & 32.5 \\
Icterus & 12 & 30.0 \\
Spider naevi & 11 & 27.5 \\
Liver: & & \\
Not papable & 40 & 100 \\
Enlarged & 0 & 0 \\
Spleen: & & \\
Normal & 8 & 20.0 \\
Enlarged & 30 & 75.0 \\
Absent & 2 & 5.0 \\
Ascites: & & \\
Absent & 8 & 20.0 \\
Mild & 16 & 40.0 \\
Moderate & 11 & 27.5 \\
Marked & 5 & 12.5 \\
\hline
\end{tabular}


Table (3): Ultrasonographic findings in studied group $(n=40)$.

\begin{tabular}{lll}
\hline Ultrasonographic data & Number $(\mathrm{n}=40)$ & $\%$ \\
\hline Liver: & & \\
• Size: & 8 & 20 \\
$\quad$ Shrunken & 32 & 80 \\
Normal size & 0 & 0 \\
Enlarged & & \\
• Echopattern: & 40 & 100 \\
Cirrhotic & 26 & 65 \\
Peroportal fibrosis & & \\
Spleen: & 8 & 20.0 \\
Normal (up to $13 \mathrm{~cm})$ & 3 & 7.5 \\
Mild enlargement $(14-16 \mathrm{~cm})$ & 13 & 32.5 \\
Moderate enlargement $(17-19 \mathrm{~cm})$ & 14 & 35.0 \\
Marked enlargement $(>19 \mathrm{~cm})$ & 2 & 5.0 \\
Absent & & \\
Portal vein: & 14 & 35.0 \\
$\quad$ Normal & 26 & 65.0 \\
Dilated ( $\geq 14 \mathrm{~m})$ & & \\
Ascites: & 8 & 20.0 \\
$\quad$ Absent & 16 & 40.0 \\
Mild & 11 & 27.5 \\
Moderate & 5 & 12.5 \\
Marked & & \\
\hline & & \\
\hline
\end{tabular}

Table (4): Initial laboratory findings and CTP score in the studied group $(n=40)$.

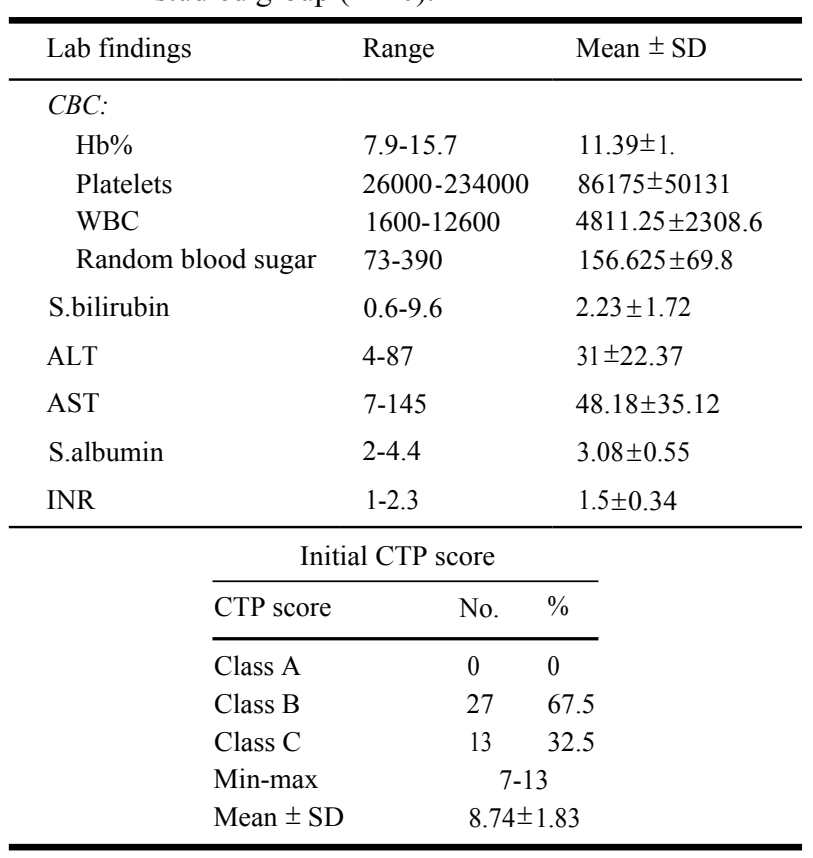

Table (5): Treatment regimen in the studied group $(n=40)$.

\begin{tabular}{lcl}
\hline Regimen & Number $(\mathrm{n}=40)$ & $\%$ \\
\hline Sofo - ledi + Riba (3 months) & 22 & 55 \\
Sofo - ledi (6 months) & 10 & 25 \\
Sofo - dacla + Riba (3 months) & 7 & 17.5 \\
Sofo - dacla (6 months) & 1 & 2.5 \\
\hline
\end{tabular}

Table (6): Comparison between laboratory findings before treatment and 12 weeks after the end of treatment $(n=30)$.

\begin{tabular}{lllll}
\hline Item & $\begin{array}{c}\text { Pre-treatment } \\
\text { mean } \pm \text { SD }\end{array}$ & $\begin{array}{c}12 \mathrm{w} \text { after end } \\
\text { of treatment } \\
\text { (SVR) } \\
\text { mean } \pm \text { SD }\end{array}$ & $\begin{array}{c}p^{-} \\
\text {value }\end{array}$ & $\begin{array}{c}\text { Signifi- } \\
\text { cance }\end{array}$ \\
\hline Hemoglobin level & $11.19 \pm 1.81$ & $10.69 \pm 2.04$ & $>0.05$ & NS \\
Platelets count & $82633.33 \pm$ & $93233.33 \pm$ & $<0.05$ & $*$ \\
Random blood sugar & 52340 & 55336 & & \\
Serum bilirubin level & $163.17 \pm 70.16$ & $149.3 \pm 55.76$ & $>0.05$ & NS \\
ALT & $35.57 \pm 23.21$ & $1.49 \pm 0.86$ & $>0.05$ & NS \\
AST & $53.7 \pm 35.99$ & $34.9 \pm \pm 13.67$ & $<0.05$ & $*$ \\
Serum albumin & $3.22 \pm 0.52$ & $3.44 \pm 0.45$ & $<0.05$ & $*$ \\
INR & $1.45 \pm 0.31$ & $1.45 \pm 0.37$ & $>0.05$ & $*$ \\
\hline
\end{tabular}

Table (7): Changes in ascetic fluid volume before treatment and 12 weeks after the end of treatment $(n=30)$.

\begin{tabular}{|c|c|c|c|c|}
\hline \multirow{2}{*}{ Item } & \multicolumn{2}{|c|}{ Pre-treatment } & \multicolumn{2}{|c|}{$\begin{array}{c}12 \mathrm{w} \text { after end of treatment } \\
\text { (SVR) }\end{array}$} \\
\hline & $\mathrm{N}$ & $\%$ & $\mathrm{~N}$ & $\%$ \\
\hline Absent & 6 & 20 & 15 & 50 \\
\hline Mild & 13 & 43.3 & 11 & 36.7 \\
\hline Moderate & 8 & 26.7 & 4 & 13.3 \\
\hline Marked (severe) & 3 & 10 & 0 & 0 \\
\hline $\begin{array}{l}p \text {-value } \\
\text { Significance }\end{array}$ & \multicolumn{2}{|c|}{$\begin{array}{l}<0.01 \\
* *\end{array}$} & \multicolumn{2}{|c|}{$<_{* *}^{<0.01}$} \\
\hline
\end{tabular}

Table (8): Use of diuretic therapy before and 6 months after achieving SVR in treated ascitic group $(n=24)$.

\begin{tabular}{llllllr}
\hline \multirow{2}{*}{ Item } & \multicolumn{2}{c}{ Before treatment } & & \multicolumn{2}{c}{$6 \mathrm{~m}$ after SVR } \\
\cline { 2 - 3 } \cline { 6 - 7 } & $\mathrm{N}$ & & & $\mathrm{N}$ & $\%$ \\
\hline On diuretics & 24 & 100 & & 14 & 58.3 \\
Off diuretics & 0 & 0.0 & & 10 & 41.6 \\
$p$-value & & \multicolumn{2}{c}{$<0.001$} & & \\
Significance & & & & & \\
\hline
\end{tabular}

Table (9): Comparison between CTP score before and 12 weeks after the end of treatment $(n=30)$.

\begin{tabular}{|c|c|c|c|c|}
\hline \multirow{2}{*}{ Item } & \multicolumn{2}{|c|}{ Pre-treatment } & \multicolumn{2}{|c|}{$12 \mathrm{w}$ after end of treatment (SVR) } \\
\hline & $\mathrm{N}$ & $\%$ & $\mathrm{~N}$ & $\%$ \\
\hline A & 0 & 0 & 9 & 30 \\
\hline B & 22 & 73.3 & 19 & 63.3 \\
\hline $\mathrm{C}$ & 8 & 26.7 & 2 & 6.7 \\
\hline $\begin{array}{l}p \text {-value } \\
\text { Significance }\end{array}$ & \multicolumn{2}{|c|}{$<0.01$} & \multicolumn{2}{|c|}{$<0.01$} \\
\hline
\end{tabular}

Table (10): Comparison between HCV RNA before treatment, $4 \mathrm{wk}, 12 \mathrm{wk}$ after initiation of treatment and $12 \mathrm{wk}$ after the end of treatment $(n=30)$.

\begin{tabular}{lllll}
\hline Item & Pre-treatment & $\begin{array}{c}\text { 4wk on tr. } \\
(\mathrm{RVR})\end{array}$ & $\begin{array}{c}\text { End of tr. } \\
(\mathrm{ETR})\end{array}$ & $\begin{array}{c}\text { 12wk after } \\
\text { tr. (RVR) }\end{array}$ \\
\hline Mean \pm SD & $\begin{array}{l}469024.675 \pm \\
71226.7\end{array}$ & 0 & 0 & 0 \\
Median & 29408.5 & 0 & 0 & 0 \\
$p$-value & & $p_{* * *}<0.001$ & $p_{* * *}<0.001$ & $p_{* * *}^{<0.001}$ \\
Significance & & & & \\
\hline
\end{tabular}


Table (11): Primary outcome of treatment with different DAAs regimen in the treated group $(\mathrm{n}=30)$.

\begin{tabular}{|c|c|c|c|c|c|c|}
\hline \multirow{2}{*}{ Regimen } & \multicolumn{2}{|c|}{$\begin{array}{c}\text { Complete } \\
\text { RVR }\end{array}$} & \multicolumn{2}{|c|}{ ETR } & \multicolumn{2}{|c|}{ SVR } \\
\hline & $\mathrm{N}$ & $\%$ & $\mathrm{~N}$ & $\%$ & $N$ & $\%$ \\
\hline Sofo - ledi + Riba ( 3 months) $\mathrm{N}=22$ & 22 & 100 & 22 & 100 & 22 & 100 \\
\hline Sofo - ledi ( 6 months) $N=10$ & 10 & 100 & 10 & 100 & 10 & 100 \\
\hline Sofo - dacla + Riba ( 3 months $) \mathrm{N}=7$ & 7 & 100 & 7 & 100 & 7 & 100 \\
\hline Sofo - dacla ( 6 months) $\mathrm{N}=1$ & 1 & 100 & 1 & 100 & 1 & 100 \\
\hline
\end{tabular}

Table (12): Incidence of treatment-related adverse events in the studied group $(\mathrm{n}=40)$.

\begin{tabular}{ccl}
\hline Adverse events & Number $(\mathrm{n}=40)$ & $\%$ \\
\hline$A$ - Minor: & & \\
Anemia $(\mathrm{n}=30)$ & 17 & 56.7 \\
Headache & 15 & 37.5 \\
Fatigue & 14 & 35.0 \\
Nausea & 13 & 32.5 \\
Itching & 10 & 25.0 \\
Fever & 9 & 22.5 \\
D.M & 1 & 2.5 \\
B- Major: & & \\
HCC & 2 & 5 \\
Death & 3 & 7.5 \\
\hline
\end{tabular}

\section{Discussion}

Analysis of the demographic data of our study group (Table 1) revealed that the age of our study group ranged from (29-76) years, with a mean age of $57 \pm 10.95$ and this is compatible with what was reported in 2 other studies $(57 \pm 9$ in Deterding et al., [6] and (53-63) years in Charlton et al., [7]).

In relation to sex, $24(60 \%)$ of our study group were males and the remaining 16 patients $(40 \%)$ were females, a finding that indicates that $\mathrm{HCV}$ infection is common among males in this area of Nile Delta.

Similar results were reported by 2 national $[8,9]$ and many other international studies $[6,7,10,11]$ who also reported increased incidence of $\mathrm{HCV}$ infection among males $(77.3 \%, 77.1 \%, 67 \%, 59 \%, 63 \%$ and $73 \%$ ) respectively.

This sex effect cannot be clearly explained, but might be related to their unique life-style subjecting them more to both schistosomal and viral liver disease.

All our patients with chronic HCV and decompensated cirrhosis (100\%) are from rural areas. This may be attributed to the increased incidence of schistosomal and viral liver disease in this endemic area across the Nile Delta.

Review of laboratory findings in our study group revealed, significant improvement in the level of serum albumin and transaminases, while a non significant improvement was observed in serum bilirubin 12 weeks after the end of treatment with almost no change in INR. A finding that indicates not only the safety of DAAs therapy regarding liver functions, but also surprisingly rapid improvement of some of liver function parameters (transaminases and serum albumin) towards restoration of normal liver functions in this group of critically ill patients. Moreover, the quick normalization of liver enzymes during and $12 \mathrm{w}$ after the end of treatment indicates marked improvement in the necroinflammatory process in the diseased liver.

Review of relevant publications revealed some discrepancies between our results and the other national and international studies. Not surprisingly, the single national study conducted by Salama et al., [12] reported similar results in a group of Egyptian HCV G4 and decompensated cirrhosis. Also, 3 other international studies $[6,7,10]$ reported improvement in liver fuctions including INR after DAAs therapy in patients with advanced cirrhosis.

By contrast, McCaughan et al., [13] reported non significant improvement in liver functions in their treated chronic hepatitis $\mathrm{C}$ patients with decompensated cirrhosis.

Meanwhile, there was a non-significant decrease in $\mathrm{Hb}$ level together with a significant increase in the platelet count $12 \mathrm{w}$ after the end of treatment compared to their baseline values. A finding that could be considered another advantage of DAAs therapy besides its efficacy, especially in this group of decompensated cirrhosis in whom cytopenia is a common finding.

Needless to say that, the non significant decrease in $\mathrm{Hb}$ level observed $12 \mathrm{w}$ after the end of treatment could be related to the use of ribavirin, however being non significant, none of our treated patients required transfusion and/or discontinuation of ribavirin. Consequently, most of these cases were managed by decreasing the ribavirin dose and in some cases addition of epoetin.

Likewise, since platelet count is an indirect marker of portal hypertension, the significant increase in the platelet count observed $12 \mathrm{w}$ after the end of treatment in our study group indicates improvement in portal hypertension in these patients.

Interestingly, before treatment, the majority $(80 \%)$ of our treated patients were ascitic $(24 / 30)$ and ascites was marked in 3 patients $(10 \%)$, mod- 
erate in 8 patients $(26.7 \%)$ and mild in 13 patients (43.3\%). After DAAs therapy, ascites was detected only in 15 patients $(50 \%)$ which was moderate in 4 patients $(13.3 \%)$ and mild in 11 patients $(36.7 \%)$ indicating marked improvement both in the incidence as well as in the volume of ascitic fluid $12 \mathrm{w}$ after the end of treatment.

It is noteworthy to mention that, on extended follow-up, 10 of our ascitic patients stopped diuretic therapy and the remaining 14 patients still on a reduced dose of diuretic therapy. Needless to say that, this marked improvement in both the frequency as well as the volume of ascites indicates not only improvement in liver functions, but also will be associated with marked improvement in the quality of life of these patients.

Review of relevant publications revealed some discrepancies between our results and the results of other studies. The single national study conducted by Salama et al., [12] also reported a significant improvement in ascites in their Egyptian HCV genotype 4 ascitic patients treated with DAAs therapy. While, the study of Deterding et al., reported a non significant improvement in ascites in their treated patients. However, McCaughan et al., [11] reported significant improvement in most of the cases and worsening of ascites in some of their treated ascitic HCV patients.

The clinically most important finding of this study is that CTP score significantly improved from $8.33 \pm 1.63$ before treatment to $7.27 \pm 01.62$ 12 weeks after the end of therapy $(p=0.05)$. A finding that has major implications in the management of HCV infection with advanced cirrhosis. This finding supports the concept that intrahepatic inflammation directly contributes to reduced synthetic capacity of the liver and that blocking inflammation can restore liver function to some extent. In view of this finding, by DAAs therapy, further progression of liver disease can potentially be halted and the number of patients requiring liver transplantation possibly can be reduced.

Similar results were also reported by the other national study [12] and 2 other international studies $[6,7]$ in whom improvement of both CTP and MELD score was observed in the majority of their treated patients.

It is noteworthy to mention that, concerning efficacy and antiviral response, the 12/24 weeks therapy with the 4 different combinations of DAAs therapy achieved SVR in all treated patients $(100 \%)$. Moreover, no virologic failure was observed in any of our treated patients. Review of relevant publications revealed some discrepancies between our results and the other international studies. Almost all other international studies reported a lower SVR rate in their patients with advanced cirrhosis treated with DAAs therapy $[6,7$, $10,11]$.

The higher SVR rate reported in our study compared to these international studies may be related to differences in sample size as well as $\mathrm{HCV}$ genotypes treated in these studies.

Regarding safety outcomes, all treatment-related adverse events were reported during the study period. The most common were minor adverse events in the form of anaemia in $17(56.7 \%)$ patients, headache in $15(37.5 \%)$ patients, fatigue in $14(35 \%)$, nausea in $13(32.5 \%)$, itching in 10 (25\%), fever in $9(22.5 \%)$ and DM in one patient $(2.5 \%)$. Most of these adverse events were managed conservatively and non of our cohort discontinued treatment prematurely or required dose adjustment of the treatment regimen.

On the other hand, 3 patients $(7.5 \%)$ died on treatment after achieving RVR, 2 from liver cell failure and one from sepsis (chest infection). Almost similar results were reported by the other national and 2 international studies. Salama et al., [12] reported 9.3\%, while McCaughan et al., [13] and Charlton et al., [7] reported $10.2 \%$ and $9.3 \%$ respectively.

Very importantly, on further subanalysis, the mean initial CTP score of the 3 patients who died during treatment in our study was 12.7 compared to $8.33 \pm 1.63$ in those patients who successfully completed treatment. Such baseline high CTP score may be considered a factor that predict mortality in patients with advanced decompensated disease who receive DAAs therapy and possibly suggesting a point of no return in these patients. It is important to note that, we need future large studies to define specific characteristics of such patients who may not benefit from these novel DAAs therapy and for whom post-transplant treatment of HCV may be a reasonable approach.

Additionally, on futher extended follow-up beyond the study period, 2 of our patients $(5 \%)$ developed HCC 6 months after achieving SVR. A finding that clearly shows that in patients with chronic hepatitis $\mathrm{C}$ and decompensated cirrhosis, HCC may still develops despite achieving a SVR. Therefore, careful monitoring and surveillance for HCC should be done even after achieving a SVR in patients with advanced cirrhosis. 
Finally, based on the results of this real-world study, it is now possible to treat patients with $\mathrm{HCV}$ and advanced decompensated cirrhosis who were largely untreated previously, the combination of different DAAs regimens with or without ribavirin for 12 or $24 \mathrm{w}$ respectively is not only highly effective with SVR12 rate of $100 \%$, but also safe and well tolerated in this group of Egyptian HCV G4 patients with decompensated cirrhosis. Moreover, the significant improvement in liver function parameters observed in this study can potentially halt progression of liver disease and consequently the number of patients requiring liver transplantation possibly can be reduced. Thus, providing a new hope for these critically ill patients. However, the timing as well as the overall approaches to treat patients with advanced decompensated liver disease remains challenging.

\section{Acknowledgements:}

We would like to thank all participants who helped during this study.

Conflict of interest: None declared.

\section{References}

1- BERTINO G., ARDIRI A., PROITI M., et al.: Chronic Hepatitis C: this and the new era of treatment, J. Hepatol., 8: 92-106, 2016.

2- REDDY K.R., BOURLIERE M., SULKOWSKI M., et al.: Ledipasvir and sofosbuvir in patients with genotype I hepatitis $\mathrm{C}$ virus infection and compensated cirrhosis: An integrated safety and efficacy analysis. Hepatology, 62: 79-86, 2015.

3- HATHORN E. and ELSHARKAWY A.M.: Management of Hepatitis $C$ genotype 4 in the directly acting antivirals era. B.M.J. Open Gastro., 3: e000112, 2016.

4- YOUNOSSI Z.M., STEPANOVA M., CHARLTON M., et al.: Patient-reported outcomes with sofosbuvir and velpatasvir with or without ribavirin for hepatitis $\mathrm{C}$ virusrelated decompensated cirrhosis: An exploratory analysis from the randomised, open-label ASTRAL-4phase 3 trial. Lancet Gastroenterol. Hepatol., 1: 122-32, 2016.

5- FLAMM S.L.: How to Treat Patients with Chronic Hepatitis C Virus Infection and Decompensated Cirrhosis. Curr. Hepatology Rep., 15: 60-6, 2016.

6- DETERDING K., HaONER ZU SIEDERDISSEN C., PORT K., et al.: Improvement of liver function parameters in advanced $\mathrm{HCJ} /$ associated liver cirrhosis by IFN-free antiviral therapies. Aliment. Pharmacol. Then., 42: 889$901,2015$.

7- CHARLTON M., EVERSON G.T., FLAMM S.L., et al.: Ledipasvir and sofosbuvir plus ribavirin for treatment of $\mathrm{HCV}$ infection in patients with advanced liver disease. Gastroenterology, 149: 649-59, 2015.

8- EL-KHAYAT H., FOUAD Y., MOHAMEDD H.I., et al.: Sofosbuvir plus daclatasvir with or without ribavirin in 551 patients with hepatitis-C related cirrhosis, genotype 4. Aliment. Pharmacol. Ther., 00: 1-6, 2018.

9- ABDEL-MONIEM A., ABOUD A., ABDEL-GABBAR M., et al.: Efficacy and safety of sofosbuvir plus daclatasvir with or without ribavirin: Large real-life results of patients with chronic hepatitis $C$ genotype 4 . Hepatology International, 12: 348-55, 2018.

10- POORDAD F., SCHIFF E.R., VIERLING J.A.I., et al.: Daclatasvir with sofosbuvir and ribavirin for hepatitis $C^{\prime}$ virus infection with advanced cirrhosis or post-liver transplantation recurrence. Hepatology, 63: 1493-505, 2016.

11-McCAUGHAN G.W., THWAITES P.A., ROBERTS S.K., et al.: Sofosbuvir and daclatasvir therapy in patients with hepatitis C-related advanced decompensated liver disease (MELD > 15). Aliment. Pharmacol. Ther., 47: 401-11, 2018.

12- ESSA M., SABRY A., SALAMA M., et al.: Impact of direct acting antiviral drugs on HCV-related decompensated liver cirrhosis. Journal of Hepatology, 68: S544S545, 2018. 


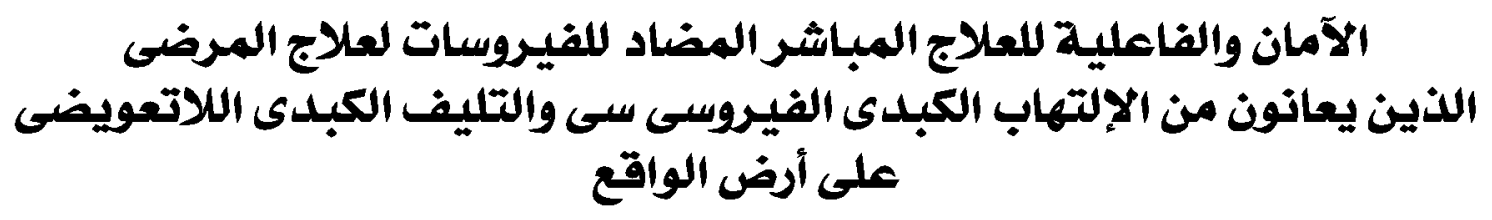

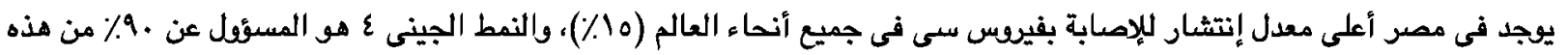

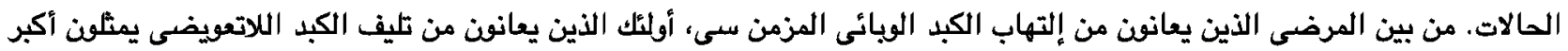
تحدى علاجى.

الهدف من البحث: هو تقييم فعالية وسلامة الآدوية المباشرة المضادة للفيروسات فى علاج مجموعة من المرضى المصريين المصابين بالإلتهاب الكبدى الفيروسى النمط الجينى ع وتليف الكبد اللاتعويضى.

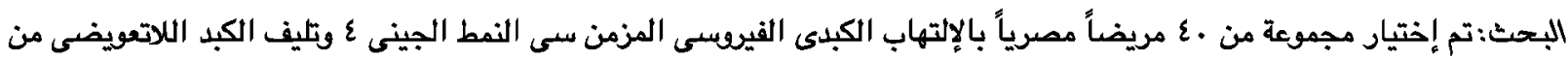

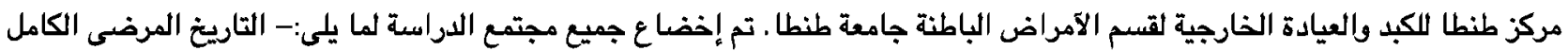

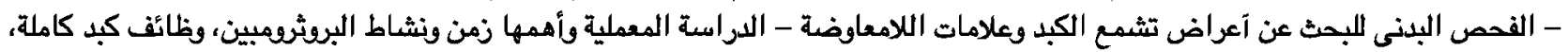

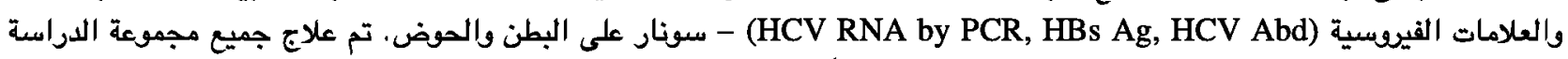

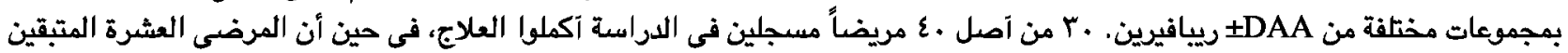
لم يفطلوا ذلك. وتوفى ب مرضى آثناء العلاج.

النتائج: العلاج قد حقق SVR فى جميع المرضى الذين آتموا العلاج (. . (\%) ولم يلاحظ أى فشل فيروسى.

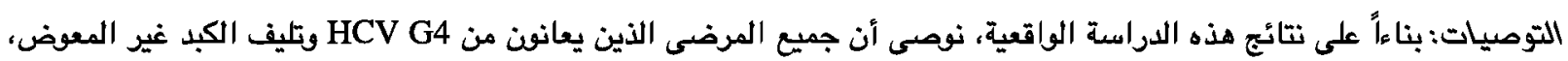

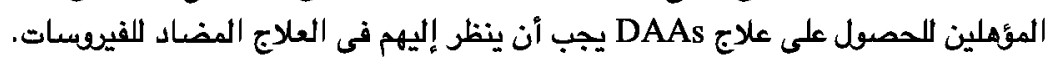

